\title{
Kinetic Release of Acetaminophen from Cross-Linked Carrageenan Hydrogel for Wound Dressing Application
}

\author{
Fatin Aliya Kasmi ${ }^{1}$, Mohd Alif Zailani ${ }^{1}$, Aznatul Jannah Abu Bakar ${ }^{1}$ and \\ Khairul Anuar Mat Amin ${ }^{1,2 *}$ (D) \\ ${ }^{1}$ School of Fundamental Science, Universiti Malaysia Terengganu, 21030 Kuala Nerus, Terengganu, Malaysia. \\ ${ }^{2}$ Advanced Nanomaterials Research Group (ANoMa), School of Fundamental Science, Universiti Malaysia \\ Terengganu, 21030 Kuala Nerus, Terengganu, Malaysia.
}

\begin{abstract}
This study investigates the compressive strength, water vapor transmission rates (WVTRs), and swelling rate of the Carrageenan (CR) hydrogel. Carrageenan hydrogel with addition of $40 \mathrm{mM} \mathrm{CaCl}$ (CR4) shows the optimum compressive strength $(7.06 \mathrm{kPa})$, ideal WVTRs $\left(1918 \pm 17 \mathrm{~g} \mathrm{~m}^{-2} \mathrm{~h}^{-1}\right)$ and better swelling behavior compared to low concentration of $\mathrm{CaCl}_{2}$. The CR4 hydrogel was further incorporated with acetaminophen (APAP) and the properties of the hydrogel were examined. The compressive strength results show the addition of APAP into CR4 hydrogel improved the stress of CR-APAP3 (CR hydrogel with $60 \%(w / w)$ of APAP) hydrogel to $10.07 \mathrm{kPa}$ than CR-APAP1 (CR hydrogel with $20 \%$ (w/w) of APAP) at 7.41 $\mathrm{kPa}$. The WVTR values increased as the concentration of APAP loaded into CR hydrogel increased. The swelling rates of CR-APAP were low at all concentrations of APAP-loaded which was at $14.5 \%$. Kinetic release of CR-APAP hydrogel was improved in which, the CR-APAP1 released almost $75 \%$ within the first 8-min, while CR-APAP2 was $40 \%$ released within the first $12-\mathrm{min}$, and CR-APAP3 released $30 \%$ within the first 13-min. In other word, it shows that higher concentration of APAP in CR prolonged the release of drug. Overall, the CR-APAP hydrogel is suitable to be applied as degradable wound dressing materials and hence, further improve patient compliance due to its fast-release behavior.

Keywords: Carrageenan, hydrogel, acetaminophen, kinetic release
\end{abstract}

*Correspondence: kerol@umt.edu.my

(Received: August 25, 2019; accepted: January 03, 2020)

Citation: Fatin Aliya Kasmi, Mohd Alif Zailani, Aznatul Jannah Abu Bakar and Khairul Anuar Mat Amin, Kinetic Release of Acetaminophen from Cross-Linked Carrageenan Hydrogel for Wound Dressing Application, J. Pure Appl. Microbiol., 2020; 14(1):271-278. https://doi.org/10.22207/JPAM.14.1.28

(C) The Author(s) 2020. Open Access. This article is distributed under the terms of the Creative Commons Attribution 4.0 International License which permits unrestricted use, sharing, distribution, and reproduction in any medium, provided you give appropriate credit to the original author(s) and the source, provide a link to the Creative Commons license, and indicate if changes were made. 


\section{INTRODUCTION}

Hydrogel is a hydrophilic polymer with three dimensional cross-linked structures and had been widely applied as controlled-release matrices to deliver drugs or cells ${ }^{1}$. Since 1960, hydrogel has been used in the field of controlled drug delivery and the research based on hydrogel has increased and became important in biomedical and pharmaceutical fields including improved the antibacterial activities ${ }^{2}$. Hydrogel is chosen as drug carrier because it can respond to surrounding conditions such as $\mathrm{pH}$, ionic strength, temperature and electric current in designing polymers for controlled drug release ${ }^{3}$. Not limited to that, other studies using the electrospun fiber as a drug carrier to shape the future of biomedical devices ${ }^{4}$ and as pharmaceutical repositories for healthcare ${ }^{4 b}$.

Carrageenan (CR) can be used as sustained-release composition because of its gelling, viscosity enhancing and proven safety properties $^{3}$. CR is soluble in water at temperature above $60^{\circ} \mathrm{C}$ but insoluble in organic solvent. $\mathrm{CR}$ is a natural thermal reversible gelling polymer that is able to melt and gel again repeatedly with only losing a little gel strength at each cycle ${ }^{5}$. The gelling strength depends on the presence of cations such as potassium ions, $\mathrm{K}^{+}$and calcium ions, $\mathrm{Ca}^{2+}$. As the number of ions increases, the gel strength also increases until it reaches the optimum level. Calcium ion is a doubly charged cation which allows it to form intermolecular ionic bridges between the sulphate groups of CR. This further stabilizes and strengthens the molecular network which leads to greater gel strength. CR is commercially used as food additive in food and dairy industries because it can act as bulking agent, carrier, emulsifier, gelling agent, humectant, stabilizer or thickener6. $\mathrm{CR}$ is also being used in pharmaceutical production of tablets ${ }^{7}$ and dietary supplement. Besides, CR has high molecular weight, high viscosity and desirable gelling property which makes it a suitable drug carrier but with limited drug loading capacity ${ }^{8}$. According to research ${ }^{9}$, kappa-CR hydrogel is $\mathrm{pH}$ sensitive and has high potential to be used in polymeric drug delivery systems.

Acetaminophen (APAP) or also known as paracetamol, is mostly used as an analgesic and antipyretic drug. It is the major ingredient in most cold and flu remedies and is generally safe for consumption at permitted doses (1000 mg per single dose and up to $4000 \mathrm{mg}$ per day for adults $)^{10}$. As analgesic drug, acetaminophen works by blocking the production of prostaglandins (hormone-like substances that are released in human body in response to illness and injury) to make the human body less aware of the injury and therefore, reduces the pain that someone experiences. For antipyretic actions, acetaminophen reduces the human body temperature by acting on the hypothalamus; a part of the brain that control body temperature ${ }^{11}$. Acetaminophen can also be loaded into a drug holder, such as hydrogel ${ }^{12}$ for drug delivery application. Factors that can affect the kinetic release of drugs are the nature of the polymer, percentage of drugs loaded into the polymer, the interaction between drugs and polymer as well as $\mathrm{pH}$ value of targeted medium. Kinetic release measurement of acetaminophen tablets made with Dioscorea alata as binders showed almost $100 \%$ release of acetaminophen within the first 30 minutes in $0.1 \mathrm{M} \mathrm{HCl}$ at $37^{\circ} \mathrm{C}^{13}$. Meanwhile, a research conducted by a group of scientists showed that kinetic release of acetaminophen depends on the $\mathrm{pH}$ value of the targeted medium ${ }^{14}$. The research indicated that the release rate of acetaminophen from carrageenan hydrogel in alkaline medium was higher than in acidic medium. There were $70 \%$ of acetaminophen released at $\mathrm{pH}$ 7.4 while only $21 \%$ acetaminophen were released at $\mathrm{pH} 1.2$ within 24 hours. This could be due to the presence of $\mathrm{OH}^{-}$group in alkaline medium which facilitates the electrostatic repulsion between carboxylate groups, thus increases the gel swelling degree and the release rate of acetaminophen. Furthermore, another research conducted indicates that pectin gel containing sorbitol sustained the release of acetaminophen in rat stomach near to $90 \%{ }^{15}$.

This study highlights the use of $C R$ hydrogel as a drug holder that was incorporated with APAP as a wound dressing material. The properties of cross-linked CR hydrogel with calcium chloride were investigated to examine the optimum properties prior incorporated with APAP. The optimum properties of $C R$ hydrogel were then incorporated with APAP and their properties such as compression, WVTRs, degradation swelling as well as kinetic release of APAP were studied. 


\section{MATERIALS AND METHODS Materials}

lota Carrageenan (Type II) (molecular weight $\approx 946.8 \mathrm{~g} / \mathrm{mol}$, product number-C1138), acetaminophen powder (purity $\approx 100.3 \%$, product number-A7085), anhydrous calcium chloride (product number-C5670), and glycerin (product number-G2289) were purchased from Sigma Aldrich, St. Louis, Missouri, USA. All materials were used without any purification.

\section{Preparation of CR-APAP hydrogel}

Blank Carrageenan (CR) hydrogel was prepared via casting method. The CR solution was prepared by dissolving $1 \%(\mathrm{w} / \mathrm{w})$ of $\mathrm{CR}$ powder in $100 \mathrm{ml}$ of distilled water, followed by glycerin at $50 \%(\mathrm{w} / \mathrm{w}$ relative to $\mathrm{CR})$ and heated for 2 hours at $70-80^{\circ} \mathrm{C}$ by using a hotplate (IKA C-MAG HS7) equipped with the stirrer. After CR was fully dissolved, different concentrations of calcium chloride at $10 \mathrm{mM}, 20 \mathrm{mM}, 30 \mathrm{mM}$ and $40 \mathrm{mM}$ were added drop-wise in the mixture and stirred for 30 minutes at $500 \mathrm{rpm}$. All the hydrogels were labelled as CR1, CR2, CR3, and CR4 respectively. CR-APAP hydrogel was synthesized via in-situ drug loading. APAPs were dissolved in distilled water $\left(40^{\circ} \mathrm{C}\right)$ at different concentrations, i.e. 20 $\%(\mathrm{w} / \mathrm{w}$ relative to $\mathrm{CR}$ ), $40 \%(\mathrm{w} / \mathrm{w}$ relative to $\mathrm{CR}$ ) and $60 \%(w / w$ relative to $C R$ ) for 30 minutes. The APAP solutions were then mixed with the CR4 (containing $40 \mathrm{mM} \mathrm{CaCl}$ ) hydrogel solution and heated for 2 hours at $70-80^{\circ} \mathrm{C}$ by using a hotplate (IKA C-MAG HS7) equipped with the stirrer. The hydrogels were being referred to as CR-APAP1 (20\% APAP), CR-APAP2 (40\% APAP) and CR-APAP3 (60\% APAP), respectively. Lastly, the hydrogels were left to dry for 24 hours at $40^{\circ} \mathrm{C}$ in oven (Memmert UF 110) before being stored at room temperature for further study.

\section{Compression Test}

Compressive measurement test was conducted by using Instron universal Testing machine (Model 3366). The cross-head speed and load were set to $10 \mathrm{~mm} / \mathrm{min}$ and $\pm 10 \mathrm{kN}$ respectively. All hydrogels were cut into $2 \mathrm{~cm} \times 2$ $\mathrm{cm}$, and the thickness of the hydrogel is at $0.5 \mathrm{~cm}$. The tests were repeated triplicates per sample for defined ratio.

Water Vapor Transmission Rate (WVTR)

The water vapor transmission rates (WVTR) of hydrogels were measured following a modified ASTM International standard method. Hydrogels of $3 \mathrm{~cm} \times 3 \mathrm{~cm}$ in dimension were fixed as a cap on a glass vial with diameter of $16 \mathrm{~mm}$ containing $10 \mathrm{ml}$ of distilled water. The vials were weighed ( $\mathrm{Wi}$ ) and kept in humidity chamber for a few hours at $37^{\circ} \mathrm{C}$ and $50 \%$ relative humidity $(\mathrm{RH})$. The vials were then removed from humidity chamber and weighed again (Wf). The measurements were done in triplicates to get the average weight. The value of WVTR was obtained by using the equation:

\section{WVTR $\left(\mathrm{g} \mathrm{m}^{-2} \mathrm{~h}^{-1}\right)=[(\mathrm{Wi}-\mathrm{Wf}) /(\mathrm{T} \times \mathrm{S})]$}

where $\mathrm{Wi}$ and $\mathrm{Wf}$ is the initial weight and final weight of vials, $T$ is duration of the measurement and $S$ is the exposed surface area of samples.

\section{Degradation}

The degradation test was carried out by immersed the hydrogel of dimension $2 \mathrm{~cm} \times 2 \mathrm{~cm}$ in $20 \mathrm{~mL}$ of phosphate buffer saline at $\mathrm{pH} 7.4$ in water bath at $37^{\circ} \mathrm{C}$ for durations of $1 / 2$ hour, 1 hour, $1 \frac{1}{2}$ hours, 2 hours, $2 \frac{1}{2}$ hours and 24 hours. The initial weight of dry sample and final weight of wet sample were measured. For the wet sample, the samples were measured after slightly being wiped by using tissue paper to expel surface solution. Degradation degree can be calculated as below:

Degradation degree $(\%)=[(\mathrm{Wf}-\mathrm{Wi}) / \mathrm{Wi}] \times 100$ where $\mathrm{Wi}$ is initial weight of dry sample before being immersed and $\mathrm{Wf}$ is final weight of wet sample after being immersed.

\section{Swelling}

The swelling test was carried out by immersing all samples $(20 \mathrm{~cm} \times 20 \mathrm{~cm})$ in phosphate buffer solution $(\mathrm{pH} 7.4)$ in water bath $\left(37 \pm 0.5^{\circ} \mathrm{C}\right)$. The samples were then removed after $24 \mathrm{~h}$, lightly blotted with a wet filter paper to expel surface solution prior to measuring the weight. The test was repeated triplicates for each ratio. Finally, the swelling degree was then determined from the equilibrium-swelling ratio:

Swelling Degree, SD (\%) $=(\mathrm{Mw}-\mathrm{Md}) / \mathrm{Md})$

where $\mathrm{Mw}=$ Weight of swollen sample and $\mathrm{Md}=$ Weight of dry sample.

\section{In-vitro Kinetic Release of Acetaminophen}

The acetaminophen release study from carrageenan hydrogel was performed via UV- 
Vis Spectrophotometer Shimadzu UV-1800. Hydrogel with the dimension of $1 \mathrm{~cm} \times 1 \mathrm{~cm}$ had been immersed in a beaker that contained $25 \mathrm{~mL}$ phosphate buffer solution ( $\mathrm{pH} 7.4)$ at ambient temperature. $3 \mathrm{~mL}$ aliquot had been taken at each designated time for measurement of absorbance of at $243 \mathrm{~nm}$ (maximum absorbance). $3 \mathrm{~mL}$ fresh phosphate buffer solution was then added to the beaker to replace the amount of aliquot taken for measurements. The amount of APAP released was calculated by interpolation from the calibration curve containing increasing concentration of acetaminophen.

\section{RESULTS AND DISCUSSION Characterization of CR-APAP Hydrogels Compression Test}

An ideal wound dressing is required to be flexible, strong, easy to handle and able to keep moist to the wound ${ }^{16}$. The mechanical properties of the hydrogel are affected by two factors: rigidity of the polymer chain and crosslinking density ${ }^{17}$. Therefore, calcium chloride at different concentrations were added to the CR hydrogel to produce cross-linked hydrogel. The low mechanical strength of the hydrogel can be enhanced by cross-linking to make the hydrogel stronger and more flexible ${ }^{18}$. This was proven based on the results obtained from the compressive test of hydrogel. Compressive test is a technique used to measure the crush resistance of the hydrogel by applying pressure to the surface of the hydrogel and recording the deformation at various loads ${ }^{19}$. Figure 1(a) and (b) show the stress-strain curves while table 1 shows the compressive stress, strain and modulus of all CR hydrogel samples. The compressive modulus increased upon the addition of calcium chloride from $0.12443 \pm 1.5 \mathrm{E}-2$ (CR1) to $0.23127 \pm 2.0 \mathrm{E}-2$ (CR4). The compressive modulus of hydrogel increased due to the increase in the crosslinking degree which lead to higher crosslinking junction points between $\mathrm{CR}$ and $\mathrm{CaCl}_{2}$. This resulted in CR hydrogel that is more elastic, flexible and compressible.

This study shows that the increased concentration of the calcium chloride lead to the increase in compressive strength of CR hydrogel. The compressive stress for CR1, CR2, CR3 and CR4 were $0.0048 \pm 3.0 \mathrm{E}-5 \mathrm{MPa}, 0.0053 \pm 2.4 \mathrm{E}-4$ $\mathrm{MPa}, 0.0066 \pm 6.9 \mathrm{E}-4 \mathrm{MPa}$ and $0.0071 \pm 3.9 \mathrm{E}-4$ $\mathrm{MPa}$, respectively. The compressive strain values of CR1, CR2 and CR3 are in the range between
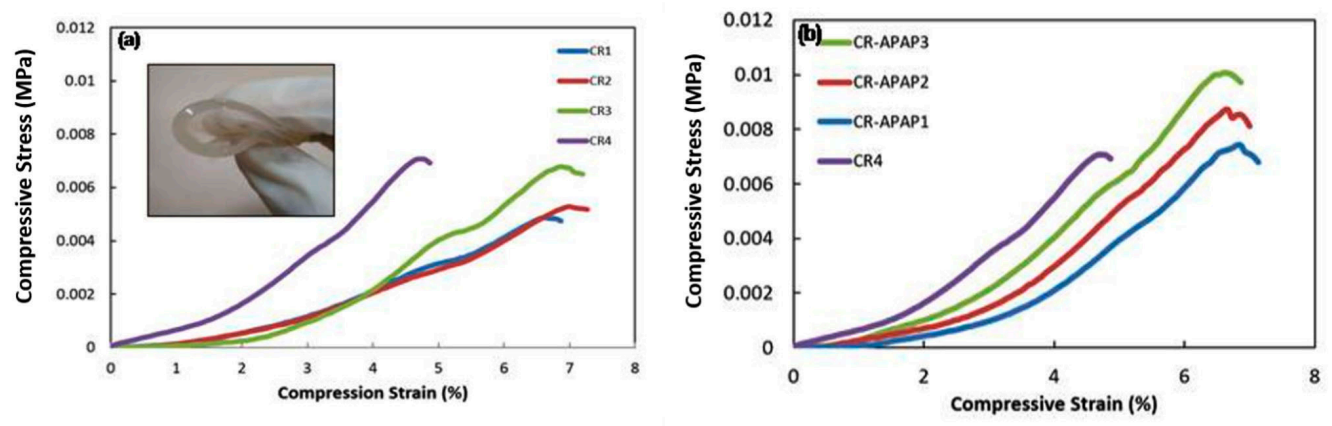

Fig. 1. (a) Stress-strain curves of CR hydrogels and (b) Stress-strain curves of CR-APAP hydrogels

Table 1. The compressive stress, strain and modulus of all samples

\begin{tabular}{lccc}
\hline Samples & $\begin{array}{c}\text { Compressive } \\
\text { Stress (MPa) }\end{array}$ & $\begin{array}{c}\text { Compressive } \\
\text { Strain (\%) }\end{array}$ & $\begin{array}{c}\text { Compressive } \\
\text { Modulus (MPa) }\end{array}$ \\
\hline CR1 & $0.00488 \pm 3.0 \mathrm{E}-5$ & $6.60 \pm 0.2$ & $0.12443 \pm 1.5 \mathrm{E}-2$ \\
CR2 & $0.00525 \pm 2.4 \mathrm{E}-4$ & $6.93 \pm 0.7$ & $0.13383 \pm 2.8 \mathrm{E}-3$ \\
CR3 & $0.00662 \pm 6.9 \mathrm{E}-4$ & $6.66 \pm 0.5$ & $0.19220 \pm 9.3 \mathrm{E}-3$ \\
CR4 & $0.00706 \pm 3.9 \mathrm{E}-4$ & $4.66 \pm 0.5$ & $0.23127 \pm 2.0 \mathrm{E}-2$ \\
CR-APAP1 & $0.00741 \pm 3.1 \mathrm{E}-4$ & $6.86 \pm 0.7$ & $0.19215 \pm 4.0 \mathrm{E}-3$ \\
CR-APAP2 & $0.00872 \pm 5.9 \mathrm{E}-4$ & $6.66 \pm 0.1$ & $0.22780 \pm 5.0 \mathrm{E}-2$ \\
CR-APAP3 & $0.01007 \pm 2.7 \mathrm{E}-3$ & $6.59 \pm 0.3$ & $0.25455 \pm 2.0 \mathrm{E}-2$ \\
\hline Journal of Pure and Applied Microbiology & \multicolumn{3}{c}{274}
\end{tabular}


$6.60 \%-6.93 \%$ while CR4 is $4.67 \%$. The increased concentration of the cross-linker further enhances the mechanical properties of the hydrogel due to the formation of double helix structure within the hydrogel that makes it more resistant to the compression applied. The study continued with CR hydrogel $\left(40 \mathrm{mM}\right.$ of $\mathrm{CaCl}_{2}$ ) incorporated with APAP at different concentrations. The compressive strength of the CR-APAP hydrogel increased, and in-contrast the compressive strain decreased as the concentration of APAP loaded into the hydrogel increased. The compressive modulus for CR-APAP1, CR-APAP2, and CR-APAP3 were 0.19215 $\pm 4.0 \mathrm{E}-3 \mathrm{MPa}, 0.22780 \pm 5.0 \mathrm{E}-2 \mathrm{MPa}$ and $0.25455 \pm$ 2.0E-2 MPa. The increased concentration of APAP produced a more elastic, flexible and strong $C R$ hydrogel which makes it suitable to be used as wound dressing.

\section{Water Vapor Transmission Rate (WVTR)}

The passage of water vapor through a CR hydrogel can be measured through WVTR. In wound dressing application, hydrogel is required to control the loss of biological fluid from the wound and maintain the moist environment surrounding the wound bed to promote healing process ${ }^{20}$. The rate of water loss from normal human skin at temperature $35^{\circ} \mathrm{C}$ is $204 \mathrm{~g} \mathrm{~m}^{-2} \mathrm{day}^{-1}$ and for injured

Table 2. Water Vapor Transmission Rates (WVTR) of CR hydrogels

\begin{tabular}{lc}
\hline Samples & WVTR $\left(\mathrm{g} \mathrm{m}^{-2} \mathrm{~h}^{-1}\right)$ \\
\hline CR1 & $2007 \pm 23$ \\
CR2 & $2053 \pm 19$ \\
CR3 & $2305 \pm 25$ \\
CR4 & $1918 \pm 17$ \\
CR-APAP1 & $112 \pm 21$ \\
CR-APAP2 & $188 \pm 13$ \\
CR-APAP3 & $305 \pm 15$ \\
\hline
\end{tabular}

skin is $279 \mathrm{~g} \mathrm{~m}^{-2}$ day $^{-121}$. The WVTR results for all CR hydrogels are shown in Table 2. CR4 had the lowest value of WVTR which is $1918 \pm 17 \mathrm{~g} \mathrm{~m}^{-2} \mathrm{~h}^{-1}$ and deem the most suitable wound dressing material. The WVTR values decrease with the addition of cross-linker due to the cross-linking junction of the double helix structure in the CR hydrogel which hindered the water diffusion ${ }^{22}$. The WVTR values should not be too high because it can cause dry condition to the wound and moist environment surrounding the wound cannot be maintained. Lower values of WVTR allow moist environment to be maintained to enhance the healing process. Wound dressing that provide moist environment is known to promote rapid healing and modern wound care products are commonly designed with these considerations ${ }^{23}$.

The WVTR values for CR-APAP samples increased as the drug loaded into CR hydrogel increased. The WVTR values for CR-APAP1, CRAPAP2 and CR-APAP3 were $112 \pm 21 \mathrm{~g} \mathrm{~m}^{-2} \mathrm{~h}^{-1}, 188$ $\pm 13 \mathrm{~g} \mathrm{~m}^{-2} \mathrm{~h}^{-1}$ and $305 \pm 15 \mathrm{~g} \mathrm{~m}^{-2} \mathrm{~h}^{-1}$ respectively. The increased values could be due to formation of a porous structure in CR-APAP which allow the flow of the water vapor or oxygen through the hydrogel. Further study needs to be done to prove the hypothesis. Good WVTR capacity of the CR hydrogel is very important for wound dressing materials because the very low WVTR value (below $100 \mathrm{~g} \mathrm{~m}^{-2} \mathrm{~h}^{-1}$ ) will cause the disturbance of healing process and also promote bacterial growth ${ }^{24}$.

\section{Degradation and Swelling Test}

Degradation is the breakdown of the CR hydrogel structure. These phenomena happen due to the presence of labile bond in the CR hydrogel that lead to hydrolysis ${ }^{25}$. Degradation has two types of modes which are surface degradation and bulk degradation. For surface degradation,

Table 3. Degradation rate of CR1, CR2 and CR3 and swelling rate of CR4 hydrogel

\begin{tabular}{lcccccc} 
Samples & \multicolumn{6}{c}{ Degradation Rate (\%) } \\
\cline { 2 - 7 } & $1 / 2 \mathrm{~h}$ & $1 \mathrm{~h}$ & $1 \frac{1}{2} \mathrm{~h}$ & $2 \mathrm{~h}$ & $21 / 2 \mathrm{~h}$ & $24 \mathrm{~h}$ \\
\hline CR1 & 5.52 & 18.83 & 25.00 & 31.70 & 31.06 & $\begin{array}{c}\text { Not accessible } \\
\text { (fully degraded) }\end{array}$ \\
CR2 & 0.53 & 2.41 & 3.24 & 1.44 & 2.19 & 58.70 \\
CR3 & 4.88 & 4.24 & 1.53 & 8.32 & 5.54 & 42.64 \\
& \multicolumn{7}{c}{ Swelling Rate (\%) } & \\
CR4 & 3.02 & 0.51 & 2.07 & 1.29 & 2.66 & -0.02 \\
\hline Journal of Pure and Applied Microbiology
\end{tabular}


it occurs on the outer surface of the hydrogel while in bulk degradation, the whole hydrogel is homogenously degrades ${ }^{25}$. From the study, CR hydrogel underwent bulk degradation due to the whole hydrogel was homogenously degraded continuously with time. The results showed that the CR hydrogel demonstrated fast degradation rate while CR4 hydrogel tend to swell as shown in Table 3. CR1 was fully degraded while for CR2 and CR3 had been degraded by $58.70 \%$ and $42.63 \%$ respectively within 24 hours. CR hydrogel degraded because it is a hydrophilic polymer, which leads to the exchange of ions with the surrounding fluid that drives the degradation of hydrogel. The degradation rate of $C R$ hydrogels decreased as the amount of calcium chloride added increased. CR with higher amount of calcium chloride had higher degree of crosslinking within its structure which reduced the amount of surrounding fluid being diffused by PBS solution. Hence, it reduced the degree of ion-exchange process between hydrogel and PBS solution that drive to degradation process. CR4 hydrogel tend to swell after $1 / 2$ hour. Overall, CR4 hydrogel was chosen to be incorporated with APAP for kinetic release measurements as it has the highest compressive modulus, highest compressive stress, lowest WVTR and shows swelling behavior compared to other samples.

For swelling test, phosphate buffer saline solution (PBS) at pH 7.4 was used as the medium. It was chosen as medium because the osmolarity and ion concentrations of the PBS solution match to those of the human body (isotonic) and also not toxic $^{19}$. The swelling rates for CR-APAP hydrogels are shown in Figure 2. The results indicate that all hydrogels were swelled up and then started to degrade after the first 1 hour. The increased swelling rate at the first 1 hour in $\mathrm{pH} 7.4$ medium of PBS solution could be due to the anion-anion repulsive electrostatic force of polymer chains ${ }^{14}$. The electrostatic repulsion of polymer chains was caused by the ionization of carboxylic acid groups

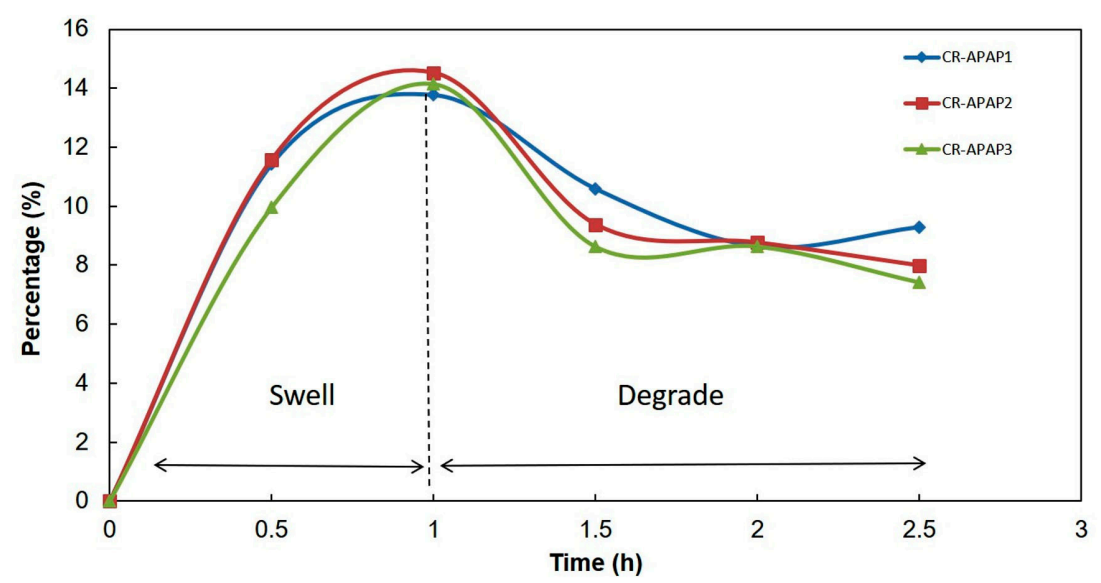

Fig. 2. Swelling rates of CR-APAP hydrogels

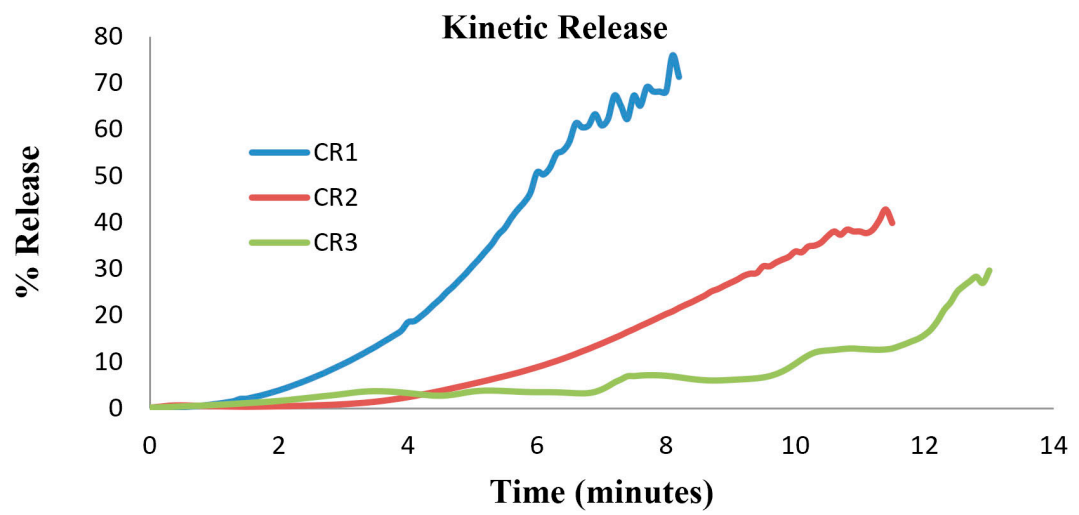

Fig. 3. Kinetic release profile of CR-APAP hydrogels 
from CR that led to the breakage of hydrogen bonds which in turn caused the network being pushed and the structure became expanded that allowed more water to diffuse ${ }^{26}$. The swelling rates decreased due to broken network of the hydrogels after 1-hour. The maximum swelling rate was shown by CR-APAP2 which was $14.5 \%$. The testing was continued for 24 hours but the result cannot be collected because all samples were degraded.

\section{Kinetic Release Study}

Kinetic release is conducted to study the movement of drug from polymeric medium of CR-APAP hydrogel to the targeted medium of wounds. Diffusional barrier and surface erosion are factors that control the kinetic release of drug. In this research, the medium used was PBS solution. The standard calibration curve of the APAP with the function of concentration versus absorbance at $243 \mathrm{~nm}$ was found to be linear within the investigation concentration range and the linear regression equation was $y=0.0654 x$ with correlation coefficient of 0.9984 . Kinetic release profiles of APAP from cross-linked CR hydrogel are shown in Figure 3. As the concentration of drug incorporated in the hydrogel increased, the longer time it is needed for CR-APAP hydrogel to fully release the drug. After 8 minutes, CR-APAP1 had released $75 \%$ of acetaminophen, compared to $40 \%$ for CR-APAP2 after 12 minutes, and $30 \%$ for CR-APAP3 after 13 minutes. The swelling and drug diffusion among the factors affecting the drug release behavior from the matrix ${ }^{17,14}$. Further study will be carried to understand the mechanism of drug release of CR-APAP hydrogel film.

\section{CONCLUSION}

The study revealed the effect of (APAP) into carrageenan (CR) hydrogels. The mechanical properties and kinetic release of the hydrogels were examined. The compression test shows the inclusion of APAP into CR hydrogels increased the strength of the material. Water vapor transmission rate (WVTR) values also increased as the concentration of APAP increased from 112 $\pm 21 \mathrm{~g} \mathrm{~m}^{-2} \mathrm{~h}^{-1}$ (CR-APAP1) to $305 \pm 15 \mathrm{~g} \mathrm{~m}^{-2} \mathrm{~h}^{-1}$ (CRAPAP3). It also shows swelling behavior improved compared to free standing CR hydrogels that tend to show degrading behavior. Lastly, the kinetic release rate increased as the drug loaded into CR hydrogels decreased. CR-APAP1 shows the highest kinetic release of APAP (75\%) compared to CRAPAP2 (40\%) and CR-APAP3 (30\%). To conclude, this study exhibited that the CR-APAP hydrogels comprise a suitable material for a degradable wound dressing material.

\section{ACKNOWLEDGMENTS}

The authors are a grateful to the School of Fundamental Science, Central Laboratory and Universiti Malaysia Terengganu for providing the facilities in undertaking this work.

\section{CONFLICT OF INTEREST}

The authors declare that there is no conflict of interest.

\section{FUNDING}

This study was supported by Fundamental Research Grant Scheme (FRGS/1/2018/STG07/ UMT/02/11) of Ministry of Education Malaysia. The funders had no role on study design, data collection and analysis, decision to publish or preparation of the manuscript.

\section{AUTHORS' CONTRIBUTIONS}

All authors listed have made a substantial, direct and intellectual contribution to the work, and approved it for publication.

\section{DATA AVAILABILITY}

All datasets generated or analyzed during this study are included in the manuscript and/or the Supplementary Files.

\section{ETHICS STATEMENT}

This article does not contain any studies with human participants or animals performed by any of the authors.

\section{REFERENCES}

1. Distantina S, Rochmadi R, Fahrurrozi M, Wiratni W. Preparation and characterization of glutaraldehydecrosslinked kappa carrageenan hydrogel. Engineering Journal, 2013; 17(3): 57-66. https://doi.org/10.4186/ ej.2013.17.3.57.

2. Li S, Dong S, Xu W, Tu S, Yan L, Zhao C, Ding J, Chen X. Antibacterial hydrogels. Advanced Science, 2018; 5(5): 1700527. https://doi.org/10.1002/advs.201700527.

3. Piyakulawat P, Praphairaksit N, Chantarasiri N, Muangsin N. Preparation and evaluation of chitosan/ carrageenan beads for controlled release of sodium diclofenac. Aaps PharmSciTech., 2007; 8(4): 120. 
https://doi.org/10.1208/pt0804097.

4. (a) Zhang Y, Ding J, Qi B, Tao W, Wang J, Zhao C, Peng $\mathrm{H}$, Shi J. Multifunctional Fibers to Shape Future Biomedical Devices. Advanced Functional Materials. 2019; https://doi.org/10.1002/adfm.201902834. (b) Feng X, Li J, Zhang X, Liu T, Ding J, Chen X. Electrospun polymer micro/nanofibers as pharmaceutical repositories for healthcare. J. Control Release, 2019.

5. Necas J, Bartosikova L. Carrageenan: a review. Veterinarni Medicina, 2013; 58(4). https://doi. org/10.17221/6758-VETMED.

6. Prajapati VD, Maheriya PM, Jani GK, Solanki HK. Carrageenan: A natural seaweed polysaccharide and its applications (vol 105, pg 97, 2014). Carbohydrate Polymers, 2016; 151: 1277-1277. https://doi. org/10.1016/j.carbpol.2016.07.050.

7. Gupta VK, Hariharan M, Wheatley TA, Price JC. Controlled-release tablets from carrageenans: effect of formulation, storage and dissolution factors. European Journal of Pharmaceutics and Biopharmaceutics, 2001; 51(3): 241-248. https://doi.org/10.1016/S09396411(01)00135-7.

8. Li L, Ni R, Shao Y, Mao S. Carrageenan and its applications in drug delivery. Carbohydrate Polymers, 2014; 103 1-11. https://doi.org/10.1016/j.carbpol.2013.12.008

9. Distantina S, Fahrurrozi M. Synthesis of hydrogel film based on carrageenan extracted from Kappaphycus alvarezii. Modern Applied Science, 2013; 7(8): 22. https://doi.org/10.5539/mas.v7n8p22.

10. Behera S, Ghanty S, Ahmad F, Santra S, Banerjee S. UVvisible spectrophotometric method development and validation of assay of paracetamol tablet formulation. J. Anal. Bioanal. Techniques, 2012; 3(6): 151-7.

11. Jozwiak-Bebenista M, Nowak JZ. Paracetamol: mechanism of action, applications and safety concern. Acta Poloniae Pharmaceutica, 2014; 71(1): 11-23.

12. Ramli N, Razak S, Amin K. In The Effect of Acetaminophen on Physical, Compression Strength and Thermal Behaviours of Kelcogel Hydrogel Films, IOP Conference Series: Materials Science and Engineering, IOP Publishing: 2018; p 012026. https:// doi.org/10.1088/1757-899X/440/1/012026.

13. Erebor J, Uhumwangho $\mathrm{M}$, Arhewoh $\mathrm{M}$, Oshoma J. Studies On The Tabletting Characteristics Of Paracetamol Tablets Using Mucilage Extracted From Dioscorea Alata. Nigerian Journal of Pharmaceutical Sciences, 2013; 12(2).

14. Soleimani F, Sadeghi M, Shahsavari H. Preparation and swelling behavior of carrageenan-graftpolymethacrylamide superabsorbent hydrogel as a releasing drug system. Indian Journal of Science and Technology, 2012; 5(2): 2143-2147.

15. Miyazaki S, Kubo W, Itoh K, Konno Y, Fujiwara M, Dairaku M, Togashi M, Mikami R, Attwood D. The effect of taste masking agents on in situ gelling pectin formulations for oral sustained delivery of paracetamol and ambroxol. International Journal of Pharmaceutics, 2005; 297(1-2): 38-49. https://doi.org/10.1016/j. ijpharm.2005.02.029.

16. Mohd SS, Abdullah MAA, Mat Amin KA. Gellan gum/clay hydrogels for tissue engineering application: Mechanical, thermal behavior, cell viability, and antibacterial properties. Journal of Bioactive and Compatible Polymers: Biomedical Applications, 2016; 31(6): 648-666. https://doi. org/10.1177/0883911516643106.

17. Costa AM, Mano JF. Extremely strong and tough hydrogels as prospective candidates for tissue repair-A review. European Polymer Journal, 2015; 72: 344-364. https://doi.org/10.1016/j.eurpolymj.2015.07.053.

18. Bukhari SMH, Khan S, Rehanullah M, Ranjha NM. Synthesis and characterization of chemically crosslinked acrylic acid/gelatin hydrogels: effect of $\mathrm{pH}$ and composition on swelling and drug release. International Journal of Polymer Science, 2015; 2015. https://doi.org/10.1155/2015/187961.

19. Ahearne M, Yang Y, Liu K. Mechanical characterisation of hydrogels for tissue engineering applications. Topics in tissue Engineering, 2008; 4(12): 1-16.

20. Muktar M, Ismail W, Razak S, Razali M, Amin K. Accelerated Wound Healing of Physically Cross Linked Gellan Gum-Virgin Coconut Oil Hydrogel Containing Manuka Honey. ASM Sci. J., 2018; 11: 166-182.

21. Kim I, Yoo M, Seo J, Park S, Na H, Lee H, Kim S, Cho C. Evaluation of semi-interpenetrating polymer networks composed of chitosan and poloxamer for wound dressing application. International Journal of Pharmaceutics, 2007; 341(1-2): 35-43. https://doi. org/10.1016/j.ijpharm.2007.03.042.

22. Straccia MC, Romano I, Oliva A, Santagata G, Laurienzo P. Crosslinker effects on functional properties of alginate/N-succinylchitosan based hydrogels. Carbohydrate Polymers. 2014; 108: 321-330. https:// doi.org/10.1016/j.carbpol.2014.02.054.

23. De Silva DA, Hettiarachchi BU, Nayanajith L, Milani MY, Motha J. Development of a PVP/kappa-carrageenan/ PEG hydrogel dressing for wound healing applications in Sri Lanka. Journal of the National Science Foundation of Sri Lanka, 2011; 39(1): 25-33. https://doi.org/10.4038/ jnsfsr.v39i1.2920.

24. Ismail NA, Mohamad SF, Ibrahim MA, Amin M, Anuar K. Evaluation of gellan gum film containing virgin coconut oil for transparent dressing materials. Advances in Biomaterials, 2014; 2014. https://doi. org $/ 10.1155 / 2014 / 351248$.

25. Fu Y, Kao WJ. Drug release kinetics and transport mechanisms of non-degradable and degradable polymeric delivery systems. Expert Opinion on Drug Delivery, 2010; 7(4): 429-444. https://doi. org/10.1517/17425241003602259.

26. Hezaveh $\mathrm{H}$, Muhamad II. Modification and swelling kinetic study of kappa-carrageenan-based hydrogel for controlled release study. Journal of the Taiwan Institute of Chemical Engineers, 2013; 44(2): 182-191. https:// doi.org/10.1016/j.jtice.2012.10.011. 